\title{
INOVAÇÃO SOCIAL NA ANÁLISE DO CICLO DE EXPANSÃo DO PROGRAMA 1 MILHÃO DE CISTERNAS
}

\author{
Carolina Beltrão de Medeiros \\ Doutora em Administração \\ Fundação Joaquim Nabuco Recife - PE - Brasil \\ carolina.beltrao@hotmail.com https://orcid.org/0000-0002-0174-9967 \\ Carla Regina Pasa Gómez \\ Doutora em Engenharia de Produção \\ Universidade Federal de Pernambuco Recife - PE - Brasil \\ carlapasagomez@gmail.com http://orcid.org/0000-0001-6182-989-X
}

\section{RESUMO}

Este artigo tem como objetivo apresentar uma análise da expansão de uma inovação social, o Programa Um Milhão de Cisternas (P1MC). A gestão do programa foi iniciada pela mobilização de um grupo pequeno de atores sociais, a partir da implantação de uma tecnologia social. O programa foi ampliado por meio de uma rede de atores organizacionais até ser institucionalizada pela Lei 12.873, de 24 de outubro de 2013, que instituiu o Programa Cisternas. A natureza do estudo é qualitativa e, para a análise dos dados coletados, foi utilizado como referencial o Modelo Teórico da Expansão de Iniciativas de Inovação Social (Medeiros, 2018) e análise de conteúdo categorial. A discussão dos dados possibilitou inferir que há uma expressiva participação dos atores organizacionais na expansão, que possibilitam melhorias na execução do programa nos territórios, concedendo este retorno como aprendizado para os atores institucionais, que também colaboram no processo de coordenação de atividades. Como conclusão, corrobora-se que o P1MC segue um percurso de expansão por meio de abordagens de gestão tanto top-down quanto bottom-up, validando-as para esta iniciativa de inovação social e ressaltando o papel fundamental exercido pelos atores organizacionais no processo. Como aprimoramento metodológico, sugere-se que o Modelo teórico da Expansão de Iniciativas de IS (Medeiros, 2018) seja aplicado em outros casos para que se possa validar, de forma mais específica, a categoria Mobilização de Atores, que está apresentada, de forma bastante genérica, e não apontou os diversos papéis que os atores assumiram durante o percurso de expansão do P1MC.

Palavras-chave: Gestão social. Inovação social bottom-up. Inovação social top-down. Mudança sistêmica. Tecnologia Social.

\section{SOCIAL INNOVATION IN SOCIAL MANAGEMENT CONTEXT: ANALYSIS OF THE EXPANSION CYCLE OF THE 1 MILLION CISTERNAS PROGRAM}

\section{ABSTRACT}

This article presents a social innovation expansion analysis, One Million Cisterns Program (P1MC). The management of the program was initiated by the mobilization of social actors in a small group, from the implementation of social technology. The program was expanded through a network of organizational actors until it was institutionalized by Law 12.873, of October 24, 2013, which instituted the Cisterns Program. The nature of the study is qualitative and data were analysed using by reference Theoretical Model for Social Innovation Initiatives Expansion (Medeiros, 2018) and categorical content analysis. The discussion of the data made it possible to infer that there is a significant participation of organizational actors in expansion, which allow improvements in territories program execution, granting this return as learning for institutional actors, who also collaborate in process of activities coordination. In conclusion, it is corroborated that P1MC follows an expansion path through both top-down and bottom-up management approaches, validating them for this social innovation initiative and highlighting the fundamental role played by organizational actors in the process. As a methodological improvement, it is suggested that Theoretical Model for Social Innovation Initiatives Expansion (Medeiros, 2018) be applied in other cases so that Actors Mobilization category can be more specifically validated, which is presented in a very general and did not point out the different roles that the actors assumed during the P1MC expansion path.

Key words: Bottom-up social innovation. Systemic change. Social management. Social Technology. Top-down social innovation.

Data da submissão: 27/05/2019

Data de aceite: $27 / 11 / 2019$ 


\section{INTRODUÇÃO}

Iniciativas de inovação social (ISs) podem ser consideradas como vetores de indução a mudanças sociais positivas (Murray, Caulier-Grice \& Mulgan, 2010). Nesta acepção, o termo "social" vem percebido como uma construção social (Turker \& Vural, 2017) em resposta a pressões da sociedade civil para melhoria do bem-estar humano e ambiental, visando à satisfação de necessidades não atendidas pelo Estado ou pelo mercado. Sendo assim, a IS não deve se manifestar necessariamente apenas no nível de interação e prática social, mas pode apresentar-se de forma concreta, como um novo produto ou uma nova tecnologia (Choi \& Majumdar, 2015) e, seguindo os preceitos da inovação aberta, pode atender à sociedade numa perspectiva mais ampla e não apenas a determinados grupos de atores.

Estudar inovação social requer considerar que o contexto territorial é fundamental tanto para o estabelecimento de premissas adotadas quanto para a análise dos problemas e soluções, pois aquilo que é prioritário para o bem-estar em um território pode diferir em relação a outros (Organização para a Cooperação e Desenvolvimento Econômico [Ocde], 2011). Além disso, considera-se que existe uma singularidade de cada processo de desenvolvimento das iniciativas de IS, que está no fato de que cada território tende a agir e reagir de forma única, em parte por conta das especificidades de sua cultura, além da questão dos atores envolvidos, que diferem em relação aos contextos específicos onde a IS poderá ser desenvolvida.

As respostas das iniciativas de IS, que vão, inicialmente, do atendimento aos problemas sociais, até o empoderamento da sociedade civil (Cajaiba-Santana, 2014), trilham o caminho de novas formas de pensamento e de organização para os contextos onde atuam, projetando novas configurações relacionais (Have \& Rubalcaba, 2016), uma vez que o Estado tem buscado como estratégia se aliar a entidades do terceiro setor e setor empresarial como forma inovadora de produzir bens públicos (Tulder, Seitanidi, Crane \& Brammer, 2016).

Os pesquisadores do Bureau of European Policy Advisers ([Bepa], 2010) consideram que as iniciativas de ISs que se expandem, tomando como ponto de partida atividades de indivíduos e/ou grupos autônomos para a definição de um projeto que passa a funcionar, de forma ampliada, em sua comunidade, podem ser consideradas como um exemplo de abordagem bottom-up da inovação social. Por outro lado, as iniciativas de ISs que se expandem tomando, como ponto de partida para seu percurso um ator externo, que pode ser o governo ou uma organização não-governamental, por exemplo, consideradas como top-down.

Sob essa perspectiva de entendimento, as iniciativas de ISs podem acontecer num contexto territorial apresentando percursos tanto de forma bottom-up quanto top-down. Nesse contexto, o importante é que elas aconteçam e atinjam os seus objetivos de promoção de bem-estar e empoderamento. Isto porque seria um risco confinar a inovação social somente às iniciativas de base.

Também pode acontecer que uma iniciativa de IS se inicie como um projeto de base e, a partir de seu movimento de expansão, se torne uma iniciativa orientada por referenciais externos e que seja institucionalizada, configurando um caso de uma iniciativa que se inicia como bottom-up, mas que, ao expandir-se, passa a apresentar configuração top-down. Um exemplo deste caso mencionado é o Programa Um Milhão de Cisternas (P1MC), que foi desenvolvido com o objetivo de gerar valor social, inicialmente por grupos de indivíduos que procuravam resolver um de seus problemas mais importantes na região semiárida brasileira, a falta de água regular para os domicílios dos habitantes desta região.

O P1MC foi criado em 1999, tendo sido inicialmente desenvolvido por pequenas comunidades da região e depois adotado como projeto pela rede Articulação Semiárido Brasileiro ([ASA], 2018), que congrega mais de três mil organizações da sociedade civil.

O programa utiliza as cisternas de placa de 16 mil litros para o abastecimento das famílias, que aprendem a construir e manter as cisternas por meio de cursos de formação, ministrados pelas

Revista de Gestão Social e Ambiental - RGSA, São Paulo, v. 13, n. 3, p. 44-59, set./dez. 2019. 
unidades executoras responsáveis. Após sua larga difusão na região semiárida como uma inovação baseada na política da estocagem da água, utilizando-se de uma tecnologia social, as cisternas, o P1MC tornou-se uma política pública institucionalizada pela Lei n.12.873 (2013) e o programa tem sido executado em parceria com unidades executoras representadas pelo Estado.

Diante do exposto, e das diversas nuances que envolvem a expansão de uma iniciativa de IS, esse estudo tem como objetivo analisar o percurso de expansão do Programa 1 Milhão de Cisternas, considerando que esta iniciativa de IS apresenta abordagens bottom-up e top-down, e que estas influenciam em sua trajetória de expansão, a fim de aprofundar o entendimento sobre as dinâmicas entre os atores que participam deste percurso e os resultados auferidos neste processo.

\section{REFERENCIAL TEÓRICO}

A inovação social tem sido amplamente discutida na literatura no que concerne às etapas de seu percurso de expansão e estas têm sido referenciadas indiretamente em análises e quadros conceituais ou diretamente apresentadas em modelos.

$\mathrm{Na}$ IS, percebida como resultado, com foco no valor social obtido por meio de uma inovação, podem-se citar os trabalhos de Bacon, Faizullah, Mulgan e Woodcraft (2008), Assogba (2010), Schmitz, Krlev, Mildenberger, Bund e Hubrich (2013); na IS percebida como processo, baseada nas capacidades dos atores (pessoas, empresas, instituições), que se relacionam entre si, destacam-se as publicações de Tardif e Harrisson (2005), André e Abreu (2006), Cajaiba-Santana (2014), Howaldt, Domanski e Kalekta (2016); e, também, sob as duas abordagens integradas, os trabalhos de Murray, Caulier-Grice e Mulgan (2010), Bepa (2010), Caulier-Grice, Davies, Patrick and Norman (2012), João (2014), Correia (2015) e Medeiros (2018).

Tardif \& Harrisson (2005) mencionaram o processo de desenvolvimento da IS como dimensão para identificação de uma iniciativa de inovação social. O referencial apresentado pelos autores não destaca estágios de desenvolvimento da IS, entretanto apresenta atributos para as dimensões de análise propostas: a) Dimensão Transformações, analisada em termos do contexto onde a IS é desenvolvida; b) Dimensão Caráter Inovador, descrita em termos da ação social que leva à formação de uma inovação; c) Dimensão Características da Inovação, relacionada ao tipo de inovação, sua abrangência e seus objetivos; d) Dimensão Atores Envolvidos, relacionada aos vários atores envolvidos no desenvolvimento e implementação de uma IS e e) Dimensão Processo de Desenvolvimento da IS, descrita em termos dos modos de coordenação, dos meios envolvidos e das restrições à sua implementação, devido às tensões entre os atores por conta de dificuldades inerentes a este processo.

O delineamento do percurso trilhado por uma IS também foi apresentado por meio de um formato geral com quatro fases em estudos de Mulgan (2006) e Mulgan, Tucker, Ali e Sanders (2007). Estas fases vão desde a criação da nova ideia, a partir do reconhecimento do problema $\left(1^{\mathrm{a}}\right.$ fase), passando pelo teste desta nova ideia na prática, o que remete a uma etapa de desenvolvimento e protótipo ( $2^{\mathrm{a}}$ fase), verificação do atributo de replicabilidade do protótipo obtido para outras realidades, com o objetivo de disseminação ampla da inovação na sociedade ( $3^{\mathrm{a}}$ fase) e uma última fase $\left(4^{a}\right)$, que seria uma espécie de melhoria contínua da inovação, agregando novos atributos a fim de atingir os objetivos inicialmente propostos.

Murray et al. (2010), em estudos posteriores ao de Mulgan et al. (2007), e utilizando-se de uma outra perspectiva para a configuração das etapas de uma IS, definem o percurso de uma iniciativa de IS em seis etapas, contemplando tanto a abordagem de processo quanto a de resultado. Este modelo foi discutido em publicações posteriores (Bepa, 2010; Caulier-Grice et al., 2012) e criticado, de forma a aprofundá-lo.

Nessa concepção, os quatro estágios iniciais do processo estão relacionados à geração de soluções, que envolve contribuições específicas das habilidades criativas para a identificação de oportunidades e o desenvolvimento de ideias e projetos, estando os dois últimos estágios 
relacionados à implementação das soluções e às estratégias utilizadas para expandí-las, a fim de ampliar seu impacto no contexto social.

Uma crítica apresentada por Murray et al. (2010) à proposta de Mulgan et al. (2007) contempla a abrangência, no modelo mais recente, das iniciativas de ISs que estão tanto vinculadas a produtos/serviços (solução tangível) quanto ao conhecimento dos atores envolvidos (solução intangível), o que significou uma ampliação do universo de iniciativas de IS consideradas na proposta. Esta diferença está expressa na quinta etapa do modelo, chamada de escala ou difusão, que caracteriza duas situações possíveis de disseminação da inovação: a difusão da inovação, referindo-se àquelas soluções que podem ser "exportadas", e a propagação da inovação, tratando-se da disponibilização de conhecimento por meio dos indivíduos e suas redes, ilustrando o que os autores consideram de "[...] forma mais adaptativa e orgânica de crescimento" (Murray et al., 2010, p.13). Outra etapa que não consta no modelo de Mulgan et al. (2007), mas que está incorporada a este, é o estágio de mudança sistêmica, que consiste na adoção de novas práticas sociais a partir da IS, com o objetivo de institucionalização.

Seguindo a mesma linha de entendimento do modelo de Murray et al. (2010), encontra-se o modelo proposto pelos pesquisadores do Bepa (2010), inclusive com similar definição das etapas, incluindo todo o processo de desenvolvimento de uma IS ao longo do tempo, que parte da IS ainda em processo de criação, possível teste e consolidação da inovação, passando pelas etapas de disseminação e mudança sistêmica como solução implementada e depois seguindo os movimentos de sua desejável evolução, ao difundir o conhecimento, processo e/ou produto para outras localidades, com vistas à institucionalização.

Os autores chamam à atenção, neste modelo, para as possibilidades de movimentos bottomup e top-down neste fluxo das iniciativas de IS. Inicialmente, imaginava-se que estas iniciativas só ocorreriam de forma promissora numa abordagem bottom-up, ou seja, uma inovação que emergisse a partir da comunidade, onde os atores sociais estariam envolvidos em um processo de aprendizado coletivo. Esta visão vem sendo debatida, pois o movimento top-down também tem emergido em determinados ambientes, sendo desenvolvido por agentes externos (instituições públicas, universidades, outros atores) na localidade onde será implementada a IS.

Quando uma iniciativa de IS ocorre em decorrência de uma política pública, pode-se encontrar que, apesar da IS ter sido implantada de forma top-down, ela teve que ser modificada ao longo do percurso de desenvolvimento e expansão por meio de adaptações promovidas pelos atores locais, configurando um movimento bottom-up para o processo. E esta "mudança de direção" do movimento só pode ser possível graças à influência do meio sobre os atores (André \& Abreu, 2006), criando as condições necessárias para que o comportamento dos atores esteja relacionado a criatividade, sensibilidade e receptividade, além de uma postura de risco favorável a inovações.

Diante dos pontos apresentados, entende-se que o percurso de uma IS é constituído de etapas (Mulgan, 2006; Mulgan et al., 2007; Murray et al., 2010; Bepa, 2010; Cajaiba-Santana, 2014), podendo culminar com a sua consolidação em uma comunidade ou território, podendo ainda difundir-se e/ou institucionalizar-se.

Medeiros (2018) apresenta uma proposta de análise de percurso de expansão de IS que considera ambas as perspectivas de processo e resultado, pois considera que não seria possível desvincular as práticas sociais construídas a partir das iniciativas de IS das respostas obtidas com estas iniciativas. Como premissa desta proposta, tem-se que o entendimento conceitual sobre as inovações sociais é que estas são fenômenos não lineares e que podem estar representadas tanto num formato tangível quanto intangível.

Considera-se que este é um modelo adequado para analisar as iniciativas de IS que já tenham sido apropriadas como prática em seus territórios e que estejam em movimento de expansão em relação à sua configuração inicial, apresentando mudanças devido às interações entre os atores e também às circunstâncias externas, que podem influenciar a trajetória destas iniciativas (Figura 1). 

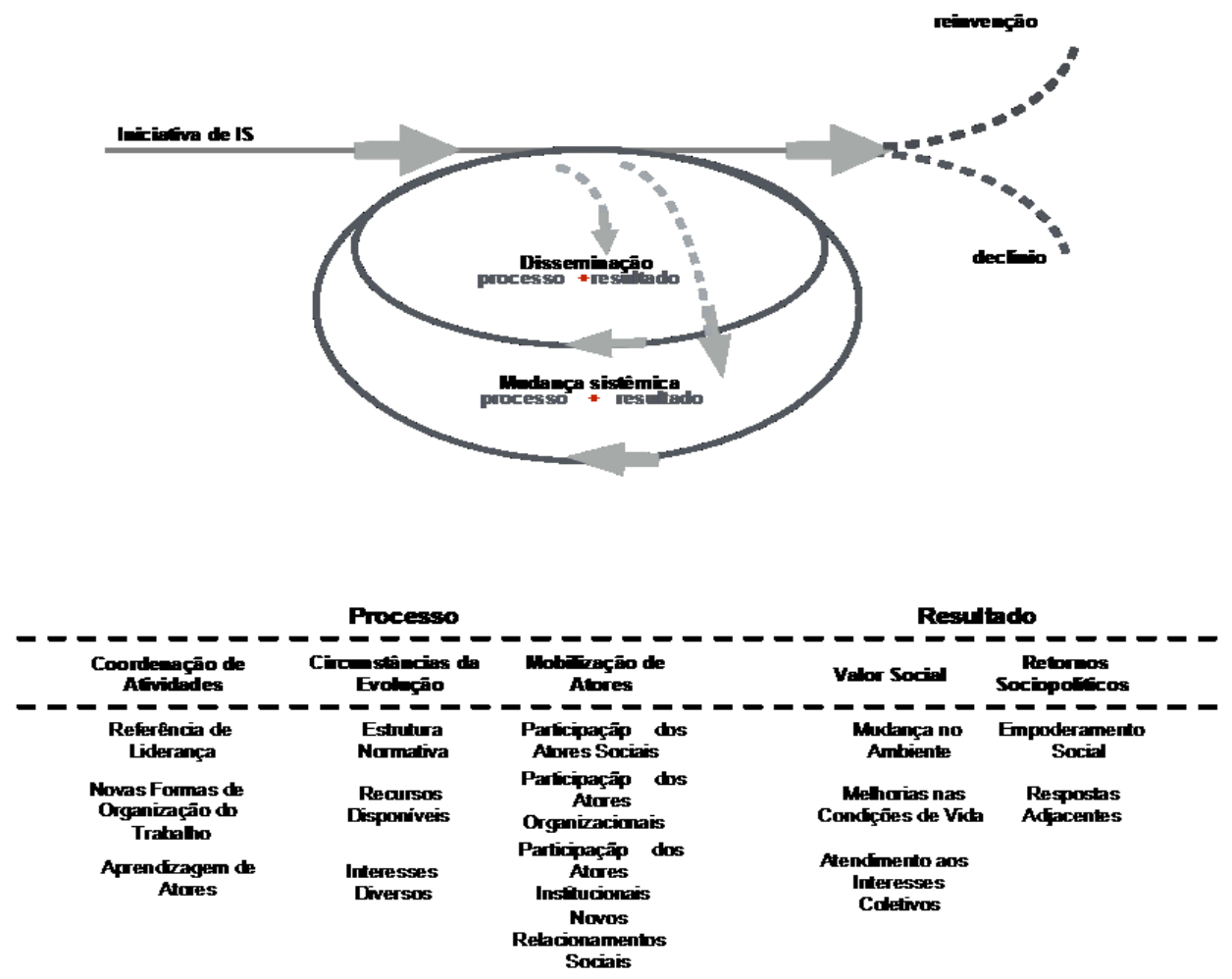

Figura 1 - Modelo Teórico da Expansão de Iniciativas de IS

Fonte: Medeiros (2018)

Na primeira etapa do modelo, "Disseminação", a iniciativa de IS já foi apropriada pelos atores, podendo a solução: 1) Ser escalonada, quando a solução experimenta a possibilidade de ser "exportada", como no caso de uma IS vinculada a produto ou serviço, e 2) Ser difundida, quando a disponibilização de conhecimento ou intervenção acontece por meio dos indivíduos e suas redes. A segunda etapa foi denominada de "Mudança Sistêmica", pois é a etapa em que a IS se institucionaliza, provocando mudanças sistêmicas na sociedade, quando novas formas de pensar e agir se organizam para se configurarem em instituições, desafiando o status quo (Medeiros, 2018).

As categorias, os indicadores e os critérios de análise para as etapas do percurso de expansão das iniciativas de IS, a partir das dimensões de processo e resultado definidas neste modelo, estão apresentados na figura 2 .

\begin{tabular}{|c|c|c|c|c|}
\hline 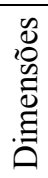 & 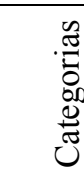 & Indicadores & Critérios de Análise & Referencial Teórico \\
\hline \multirow{2}{*}{ 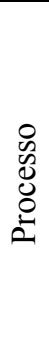 } & \multirow{2}{*}{ 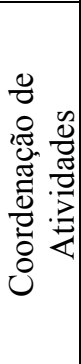 } & $\begin{array}{l}\text { Referência de } \\
\text { liderança }\end{array}$ & $\begin{array}{l}\text { Atores que assumem posições de liderança, } \\
\text { trabalhando no sentido de coordenar as atividades } \\
\text { relacionadas a esta iniciativa, ocupando, em } \\
\text { diversas oportunidades, papéis protagonistas no } \\
\text { processo }\end{array}$ & $\begin{array}{l}\text { - Assogba (2010); } \\
\text { - Bepa (2010). }\end{array}$ \\
\hline & & $\begin{array}{l}\text { Novas formas } \\
\text { de organização } \\
\text { do trabalho }\end{array}$ & $\begin{array}{l}\text { Formas inovadoras de divisão e coordenação do } \\
\text { trabalho, o que resulta na geração de novas práticas } \\
\text { sociais, criadas a partir de ações coletivas } \\
\text { e intencionais }\end{array}$ & $\begin{array}{l}\text { - Lévesque (2002); } \\
\text { - Caulier-Grice et al. } \\
\text { (2012); } \\
\text { - Cajaiba-Santana (2014). }\end{array}$ \\
\hline
\end{tabular}




\begin{tabular}{|c|c|c|c|c|}
\hline & & $\begin{array}{l}\text { Aprendizagem } \\
\text { de atores }\end{array}$ & $\begin{array}{l}\text { Participação e interação dos atores envolvidos, que } \\
\text { passam a adquirir conhecimento necessário para as } \\
\text { ações pretendidas, por meio de troca de } \\
\text { conhecimento e experiências, estando esta } \\
\text { aprendizagem refletida em novas habilidades para } \\
\text { estes atores }\end{array}$ & $\begin{array}{l}\text { - Rollin \& Vincent } \\
(2007) \text {; } \\
\text { - Caulier-Grice et al. } \\
\text { (2012); } \\
\text { - Howaldt, Domanski \& } \\
\text { Kaletka (2016). }\end{array}$ \\
\hline & $\begin{array}{ll}\pi \\
\tilde{z} & 0\end{array}$ & $\begin{array}{l}\text { Estrutura } \\
\text { normativa }\end{array}$ & $\begin{array}{l}\text { Acordos informais, normas e leis existentes que } \\
\text { possam ter relações com o contexto onde está } \\
\text { sendo desenvolvida uma iniciativa de IS }\end{array}$ & $\begin{array}{l}\text { - Tardif \& Harrisson } \\
(2005) ; \\
\text { - Assogba (2010). }\end{array}$ \\
\hline & 䜦 & $\begin{array}{l}\text { Recursos } \\
\text { disponíveis }\end{array}$ & $\begin{array}{l}\text { Conhecimento (as habilidades dos atores), estrutura } \\
\text { física, recursos econômicos, entre outros - } \\
\text { disponíveis para a dinâmica de uma iniciativa de IS }\end{array}$ & - Murray et al. (2010) \\
\hline & : & $\begin{array}{l}\text { Interesses } \\
\text { diversos }\end{array}$ & $\begin{array}{l}\text { Olhares diversos dos atores envolvidos na dinâmica } \\
\text { de uma iniciativa de IS }\end{array}$ & Assogba (2010) \\
\hline & E्ठ & $\begin{array}{l}\text { Participação dos } \\
\text { atores sociais }\end{array}$ & $\begin{array}{l}\text { A forma como ocorre a participação dos grupos de } \\
\text { indivíduos, cooperativas, associações, sindicatos e } \\
\text { movimentos sociais }\end{array}$ & $\begin{array}{l}\text { Tardif \& Harrisson } \\
(2005)\end{array}$ \\
\hline & $\begin{array}{l}\stackrel{0}{<} \\
\infty \\
0 \\
0 \\
0\end{array}$ & $\begin{array}{l}\text { Participação dos } \\
\text { atores } \\
\text { organizacionais }\end{array}$ & $\begin{array}{l}\text { A forma como pode ocorrer a participação das } \\
\text { empresas, ONGs e empreendimentos sociais }\end{array}$ & $\begin{array}{l}\text { Tardif \& Harrisson } \\
(2005)\end{array}$ \\
\hline & :్ָ & $\begin{array}{l}\text { Participação dos } \\
\text { atores } \\
\text { institucionais }\end{array}$ & $\begin{array}{l}\text { A forma como pode ocorrer a participação do } \\
\text { Estado, Universidade e demais instituições }\end{array}$ & $\begin{array}{l}\text { Tardif \& Harrisson } \\
(2005)\end{array}$ \\
\hline & $\sum^{0}$ & $\begin{array}{l}\text { Novos } \\
\text { relacionamentos } \\
\text { sociais }\end{array}$ & $\begin{array}{l}\text { Novos tipos de relacionamentos a partir da rede de } \\
\text { colaboração entre os atores sociais e/ou } \\
\text { organizacionais e/ou institucionais }\end{array}$ & Cajaiba-Santana (2014) \\
\hline & & $\begin{array}{l}\text { Mudança no } \\
\text { ambiente }\end{array}$ & $\begin{array}{l}\text { O ambiente pode incorporar novos componentes, } \\
\text { resultantes das práticas sociais emergentes da } \\
\text { iniciativa de IS }\end{array}$ & Correia (2015) \\
\hline & $\frac{\pi}{0}$ & $\begin{array}{lr}\text { Melhorias } & \text { nas } \\
\text { condições } & \text { de } \\
\text { vida } & \end{array}$ & $\begin{array}{l}\text { Melhorias nas condições de vida, observadas para } \\
\text { os atores sociais beneficiários destas iniciativas }\end{array}$ & $\begin{array}{l}\text { - Cloutier (2003); } \\
\text { - Borges (2017). }\end{array}$ \\
\hline & $\frac{\dot{2}}{\dot{0}}$ & $\begin{array}{l}\text { Atendimento } \\
\text { aos interesses } \\
\text { coletivos }\end{array}$ & $\begin{array}{l}\text { Atendimento aos interesses coletivos dos atores } \\
\text { envolvidos, onde os resultados surgem como novas } \\
\text { dinâmicas para problemas sociais concretos, } \\
\text { vividos localmente e considerados como } \\
\text { formadores de quadros insatisfatórios para a } \\
\text { localidade }\end{array}$ & $\begin{array}{l}\text { - Cloutier (2003); } \\
\text { - Correia (2015). }\end{array}$ \\
\hline 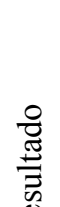 & 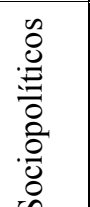 & $\begin{array}{l}\text { Empoderamento } \\
\text { social }\end{array}$ & $\begin{array}{l}\text { Uma consequência da própria atuação dos atores } \\
\text { que, devido à rede de aprendizagem e } \\
\text { conhecimentos adquiridos, passam por um processo } \\
\text { de fortalecimento social e que pode refletir-se em } \\
\text { contextos semelhantes }\end{array}$ & $\begin{array}{l}\text { - Caulier-Grice et al. } \\
(2012) \text {; } \\
\text { - Horst \& Freitas (2016) }\end{array}$ \\
\hline $\mathscr{2}$ & 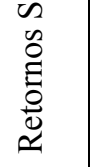 & $\begin{array}{l}\text { Respostas } \\
\text { adjacentes }\end{array}$ & $\begin{array}{l}\text { Respostas para a sociedade relacionadas às novas } \\
\text { práticas, onde estas respostas podem ser de } \\
\text { natureza cultural e/ou ambiental e/ou econômica } \\
\text { e/ou relacional }\end{array}$ & Correia (2015) \\
\hline
\end{tabular}

Figura 2 - Dimensões, categorias, indicadores e critérios de análise do Modelo Teórico da Expansão de Iniciativas de Inovação Social

Fonte: Medeiros (2018)

Considerando os critérios de análise atribuídos aos indicadores das categorias que compõem as dimensões de processo e resultado, entende-se que o objetivo deste modelo é definir um ponto de partida para as discussões das iniciativas de ISs nas etapas "Disseminação" e "Mudança Sistêmica" do percurso de expansão, destacando aspectos que podem ser considerados como importantes para seu êxito, fracasso ou estagnação. 


\section{MÉTODOS DE PESQUISA}

Esta investigação possui natureza qualitativa, com fins exploratório-descritivos, uma vez que pretende desenvolver, esclarecer e modificar conceitos e ideias relativos aos conteúdos desenvolvidos sobre o tema da IS, avançando no conhecimento sobre a problemática apresentada (caráter exploratório) e descrever, por meio dos resultados obtidos, as características do processo em pauta (caráter descritivo) (Gil, 2010).

O método utilizado escolhido como mais adequado para a análise em questão foi o estudo de caso, seguindo a tendência das pesquisas em inovação, que apresentam ênfase nas pesquisas longitudinais e em estudos de caso em profundidade (Lopes, Vieira, Barbosa \& Parente, 2015). As evidências empíricas estão divididas entre dados secundários (documentos e artefatos) e dados primários (observações e entrevistas).

A coleta de dados primários foi realizada com atores envolvidos diretamente no P1MC, por meio de entrevistas semiestruturadas e observação não participante, em que a distância do pesquisador da situação observada é reduzida, tornando-se um instrumento essencial da coleta de dados (Flick, 2009). A observação não participante aconteceu na forma de visitas à unidade da ASA Brasil em Recife, quando a pesquisadora pôde ter contato com o funcionamento da rede e conhecer alguns representantes de unidades executoras (atores organizacionais) do caso em pauta.

No que concerne às entrevistas, de natureza semiestruturada, as perguntas realizadas junto aos atores foram baseadas nos indicadores apontados no Modelo Teórico da Expansão de Iniciativas de IS (Medeiros, 2018), considerando as suas dimensões de processo e resultado. A indicação dos atores entrevistados foi realizada por meio da técnica da bola de neve - as pessoas entrevistadas inicialmente (escolhidas pela pesquisadora) indicaram outros atores que eles julgavam adequados para contribuir com o caso em estudo, devido ao seu conhecimento sobre o assunto.

Em seguida, a figura 3 apresenta o grupo de entrevistados relativo ao Programa 1 Milhão de Cisternas (P1MC).

\begin{tabular}{|l|l|l|l|l|}
\hline $\begin{array}{l}\text { Código } \\
\text { pesquisa }\end{array}$ & Órgão de Atuação & $\begin{array}{l}\text { Função } \\
\text { desempenhada }\end{array}$ & $\begin{array}{l}\text { Formato da } \\
\text { entrevista }\end{array}$ & $\begin{array}{l}\text { Duração da } \\
\text { entrevista }\end{array}$ \\
\hline E01_EC2 & $\begin{array}{l}\text { Associação Programa 1 Milhão } \\
\text { de Cisternas (AP1MC) Recife }\end{array}$ & $\begin{array}{l}\text { Assessor de } \\
\text { Coordenação }\end{array}$ & Presencial & $1 \mathrm{~h} 30 \mathrm{~min}$ \\
\hline E02_EC2 & AP1MC Recife & Assessor técnico & Presencial & $1 \mathrm{~h} 30 \mathrm{~min}$ \\
\hline E03_EC2 & $\begin{array}{l}\text { Associação Agroecológica } \\
\text { Bom Jardim }\end{array}$ & Coordenador & $\begin{array}{l}\text { Skype com } \\
\text { vídeo }\end{array}$ & $39 \mathrm{~min}$ \\
\hline E04_EC2 & Centro Sabiá & $\begin{array}{l}\text { Coordenador } \\
\text { Geral }\end{array}$ & Presencial & $54 \mathrm{~min}$ \\
\hline E05_EC2 & Embrapa Semiárido & Pesquisador & $\begin{array}{l}\text { Whatsapp } \\
\text { com vídeo }\end{array}$ & 57 min \\
\hline E06_EC2 & $\begin{array}{l}\text { Coordenação Geral de Acesso à } \\
\text { Água - subordinada ao } \\
\text { Ministério do Desenvolvimento } \\
\text { Social (MDS) }\end{array}$ & Coordenador & $\begin{array}{l}\text { Telefone } \\
\text { convencional }\end{array}$ & 47 min \\
\hline
\end{tabular}

Figura 3 - Entrevistados

Fonte: Dados da Pesquisa (2018)

Considerou-se que as entrevistas concedidas pelos atores organizacionais foram suficientes para atender aos objetivos da pesquisa, tendo sido entrevistados representantes de organizações nãogovernamentais que têm participado da execução do programa (E03_EC2 e E04_EC2), tanto em nível operacional quanto intermediário (E01_EC2 e E02_EC2). Âlém disso, foi ouvido um representante do Estado, relacionado diretamente à gestão do programa de governo responsável pelo P1MC (E06_EC2) e um pesquisador especialista em gestão hídrica, que explanou sobre avaliações técnicas realizadas no programa (E05_EC2). 
A análise dos dados das entrevistas foi realizada por meio de análise de conteúdo categorial, que funciona por meio do desmembramento do texto em categorias segundo reagrupamentos analógicos, tendo por finalidade a interpretação destas comunicações (Bardin, 2011). Como suporte operacional, foi utilizado o software NVivo para a codificação dos dados.

A partir desta análise inicial, houve uma análise comparativa dos resultados, tomando-se como referencial teórico o conjunto dos indicadores propostos no Modelo Teórico da Expansão de Iniciativas de Inovação Social (Medeiros, 2018), apresentado na Figura 1. Considerou-se que o programa apresentava-se institucionalizado, encontrando-se em fase de "Mudança Sistêmica" em relação ao Modelo.

\section{DISCUSSÃO DOS RESULTADOS}

Com base nos dados obtidos nesta pesquisa, apresenta-se uma análise do processo contínuo de expansão do P1MC, vista sob a ótica dos indicadores do Modelo Teórico da Expansão de Iniciativas de Inovação Social (Medeiros, 2018).

No que se refere à dimensão Processo, a análise será iniciada pela categoria Coordenação de Atividades. Em relação ao indicador Referência de Liderança, tem-se que mesmo sendo o P1MC um programa institucionalizado e gerido pelo governo, a ASA Brasil (ator organizacional) representa um papel protagonista, devido à sua vivência política de debates e articulação pelo semiárido, como destaca o Entrevistado 06.

Ela tem um papel importante nesse processo, que vai além da execução. Pelo próprio histórico. É uma organização que tá com parceria com o governo federal desde 2002, né? Então, assim, não tem nenhum outro parceiro do programa que tenha tanto tempo de execução de forma conjunta com o Estado brasileiro. Então é esse o diferencial (E06_EC2).

No que concerne a um nível micro de análise, considerando-se o papel dos atores organizacionais locais, as unidades executoras do programa, que lidam com as famílias beneficiárias, as referências de liderança para o P1MC, apresentam-se como as referências de liderança das comunidades, que interagem diretamente com estas unidades. Com relação a atores institucionais, pode-se destacar o papel do Governo Federal, uma vez que tem sido o principal agente de fomento do P1MC.

No que se refere às Novas Formas de Organização do Trabalho, o Novo Marco Legal para a implementação do Programa Cisternas tem sido considerado como uma nova forma de conceber a gestão do programa, tendo sido projetado pelo Governo Federal com o objetivo de melhorar este processo. Além disso, foi reconhecido o papel das tecnologias sociais, com definição legal e normativa (Escola Nacional de Administração Pública [Enap], 2016).

Este marco, que entrou na Medida Provisória no 619, de 06 de junho de 2013, também foi definido visando a institucionalizar a ação no Governo Federal e surgiu a partir de reuniões com vários atores que participaram historicamente do programa, como a ASA Brasil. Assim, a partir deste marco regulatório, foi possível ao Governo Federal reconhecer as especificidades do processo e formalizá-lo por meio de regras que simplificassem e tornassem padronizados procedimentos associados à celebração de parcerias, contratação e execução dos atores envolvidos e também da prestação de contas (Enap, 2016), como destaca o Entrevistado 01: “Aí teve a história do Marco Legal, do marco regulatório das organizações e aí esses convênios passaram a ser contrato. Então, a gente faz a cisterna, faz a tecnologia por produto" (E01_EC2).

Com relação às famílias beneficiadas pelo programa, embora a escolha esteja vinculada ao Cadastro Único do Governo Federal, esta indicação tem sido refinada em nível local, por meio das unidades executoras, no caso da ASA Brasil, e outras entidades. Nesse contexto, torna-se destacada a capacidade da ASA Brasil, devido à sua grande experiência, de sair vitoriosa na maioria dos editais lançados pelo Governo Federal para a construção de cisternas em detrimento aos governos, que experimentam alguns entraves burocráticos. Assim, embora que a ASA Brasil assuma um

Revista de Gestão Social e Ambiental - RGSA, São Paulo, v. 13, n. 3, p. 44-59, set./dez. 2019. 
protagonismo na gestão intermediária do $\mathrm{P} 1 \mathrm{MC}$, outras entidades também estão aptas a realizar esta gestão, por conta do arcabouço normativo do programa, que torna os processos mais padronizados e independentes da gestão direta da ASA.

No tocante ao indicador Aprendizagem de Atores, existem três pontos a serem destacados. O primeiro, é em relação ao aprendizado do Governo Federal, a partir dos processos participativos desenvolvidos pela ASA Brasil. É importante citar neste percurso a contrapartida do governo, que passou a fornecer subsídios organizacionais para que o programa pudesse ter maior racionalidade em seus processos, facilitando a sua expansão. Neste âmbito, houve um aumento significativo de velocidade na construção de cisternas. Os convênios executados sob os instrumentos definidos com base no novo arcabouço legal promoveram uma entrega duas vezes mais rápida do que pelo formato (Enap, 2016).

O segundo ponto diz respeito à aprendizagem das famílias beneficiárias, que não mudou de forma qualitativa, pois o programa em termos conceituais continua o mesmo. E o terceiro diz respeito às unidades executoras locais, que passam a ter, nesse processo, uma aprendizagem vinculada não só às diretrizes da ASA, como também à normatização dos processos do Programa Cisternas, criando suas próprias dinâmicas locais de execução, conforme depoimento do Entrevistado 06.

\begin{abstract}
Claro que a ASA, pela expansão que ela tem, ela consegue organizar melhor os processos, consegue trabalhar bem essas inovações que surgem em nível local, mas na minha visão, pelo que eu já conheci dessas organizações, isso é um processo que não tá integrado, não tá associado diretamente com a ASA em si. Tá muito mais associada com a dinâmica local mesmo (E06_EC2).
\end{abstract}

Ao analisar a categoria Coordenação de Atividades como um todo, observou-se que o fluxo de atividades do programa, impactado pela lei federal que normatizou as suas atividades, mas que não mudou a essência do programa em relação às práticas dos atores locais, acontece com destaque para os atores organizacionais (ASA Brasil), que interagem tanto aprendendo com os atores sociais como ensinando novas práticas aos atores institucionais.

$\mathrm{Na}$ Categoria Circunstâncias da Evolução, no que se refere ao indicador Estrutura Normativa, destaca-se, como ponto expoente para o crescimento acelerado do P1MC, a decisão de universalização do acesso à água do Governo Federal. A partir daí, com a necessidade de expansão em maior escala do programa, surge a necessidade de formalizar o processo do P1MC em lei. E a Lei $n^{\circ} 12.873$ (2013) vem corroborar a necessidade de melhorar os processos existentes, uma vez que o programa torna-se uma política de Estado.

Neste caso, observa-se um claro relacionamento de interseção em alguns pontos entre os indicadores Estrutura Normativa e Novas Formas de Organização do Trabalho. Esta confluência é representada pela nova lei, que passa por um grau de formalização e regulamentação jurídica, implicando em novos procedimentos de execução.

No que concerne ao indicador Recursos Disponíveis, ao mesmo tempo em que o governo cita as benesses da expansão em maior grau realizada em parceria com as entidades da sociedade civil, estas últimas ressaltam também a incerteza sobre o montante do orçamento da União reservado para o programa, que tem representado o sustento para a maior parte das unidades executoras, as organizações de ponta do fluxo de execução, conforme depoimento do Entrevistado 03.

A partir do programa [P1MC], a gente pôde também manter algumas atividades, por exemplo: internet, água, energia. Então, os programas contemplam isso, contemplam uma equipe mínima, como eu falei, né, que dá suporte, que dá subsídio pra a gente executar esses programas. (E03_EC2)

Revista de Gestão Social e Ambiental - RGSA, São Paulo, v. 13, n. 3, p. 44-59, set./dez. 2019. 
Um ponto de destaque da análise foram as dificuldades de caráter externo em relação à continuidade da expansão do programa, devido as novas configurações políticas de governo, o que trouxe uma grande insegurança para estas unidades executoras, mesmo com o programa estando institucionalizado.

Outro indicador que aponta sobre as circunstâncias da evolução trata dos Interesses Diversos, apresentando multiplicidade de pontos de vista e ações sobre o P1MC proveniente dos seus atores. Um destes interesses, neste caso conflitante em relação à ASA Brasil, expõe o desejo do governo, antes da institucionalização do programa, de romper com a ASA para, ao invés de promover a construção de cisternas de placa, instalar cisternas de plástico pois "[...] go governo achou que poderia chegar o mais rápido possível a um milhão de famílias se instalasse cisternas de plástico" (E04_EC2).

$\mathrm{Na}$ análise da categoria Circunstâncias da Evolução, destaca-se a atuação dos atores institucionais no planejamento da expansão e gestão das receitas fixas, a fim de garantir a execução da iniciativa e um realinhamento dos processos existentes no P1MC a partir de discussões entre os principais atores envolvidos. Consequentemente, os atores organizacionais, envolvidos no processo e gestores da iniciativa junto aos atores sociais, assumiram a função de aprimorar e difundir a estrutura normativa existente.

A categoria Mobilização dos Atores chama a atenção para o papel dos envolvidos no percurso da expansão da iniciativa de IS. O primeiro indicador, que retrata a Participação dos Atores Sociais neste percurso de expansão, ressalta a participação ativa das famílias beneficiárias, que continuou após o processo de institucionalização do $\mathrm{P} 1 \mathrm{MC}$, devido às ações de capacitação para construção e manutenção das cisternas e o empoderamento proporcionado pela iniciativa. $\mathrm{O}$ depoimento do Entrevistado 03 ilustra bem esta participação.

Então, ela [a família beneficiária] participa dos dias de curso, aí ela se envolve na história da escavação do buraco, na hora da construção, em fazer a massa, porque ela vai valorizar o que ela tá recebendo. Então, a participação da família é de forma muito ativa. Na hora de pintar a cisterna, ela ajuda. Então, com o pedreiro também, tem o diálogo com o pedreiro. Muitas das famílias que tão nessa mobilização também são pedreiros, os filhos dos agricultores também fazem um curso de GRH [Gerenciamento de Recursos Hídricos], então fica tudo dentro das comunidades, dentro do município (E03_EC2).

No tocante à Participação dos Atores Organizacionais, ao se institucionalizar o P1MC, com a finalidade de expansão, observam-se quatro tipos de atores organizacionais: a ASA, os governos estaduais e os governos municipais como organizações intermediárias e as unidades executoras, que podem ser empreendimentos sociais, como organizações da ponta, de execução. $\mathrm{O}$ contato direto com as famílias é realizado por estas unidades, que fazem o papel replicador da metodologia do P1MC e promovem algumas adaptações necessárias, a depender das especificidades da região onde o programa está sendo implantado. A ASA, operacionalizada pela AP1MC, vai se organizando ao longo do tempo de forma mais estruturada devido à expansão do programa, mas passa a exercer um papel de caráter intermediário e também regulador do processo.

Relativamente à Participação dos Atores Institucionais, a primeira participação é do Governo Federal, exercendo papel de financiador da política pública. E, a partir dessa participação mais efetiva, em que as famílias e as unidades executoras passam a ter conhecimento desse papel do Estado de apoio à atividade, que fica reforçada numa perspectiva diferente do Estado em relação à sociedade, de aceitação da mudança social.

Os Novos Relacionamentos Sociais também são destacados nesta configuração de expansão da iniciativa, consistindo nos novos relacionamentos que surgem entre os grupos de atores, destacando-se o protagonismo da sociedade civil, conforme relato do Entrevistado 06.

Eu acho, assim, talvez esse programa, ele seja uma das experiências de maior escala de parcerias envolvendo entes públicos, Estado e sociedade civil. No Brasil, eu não conheço outra experiência que tenha uma relação tão próxima [...] entre esses dois atores com a 
sociedade civil. (E06_EC2).

Ao analisar a categoria Mobilização dos Atores, corrobora-se para o P1MC que os atores de uma iniciativa de IS vão assumindo diferentes papéis ao longo do seu percurso de expansão (André \& Abreu, 2006). Os papéis assumem sobreposições, pois alguns atores organizacionais muitas vezes assumem papéis de beneficiários e, atores institucionais, de executores (que seriam, $a$ priori, papéis de um ator organizacional). No P1MC, entende-se que muitas vezes o papel do Governo Federal tem sido não só de fomentador mas de executor da iniciativa; e a ASA tem assumido um papel regulador da expansão, representando os atores sociais (beneficiários).

Após analisar as categorias relativas à dimensão Processo, considerando-se os elementos de influência sobre os indicadores, inicia-se a análise da dimensão Resultado, apresentando-se primeiramente a categoria Valor Social. O primeiro indicador da categoria discute sobre a Mudança no Ambiente, que vem atrelada à questão da configuração física. $\mathrm{O}$ depoimento do Entrevistado 02 ressalta esta mudança.

Se você pegar hoje o Google e sobrevoar o semiárido, o pontinho branco hoje faz parte do quintal. [...] Do mesmo jeito que tem lá o plantio, do mesmo jeito que tem lá uma hortinha, uma criação, [a cisterna] faz parte hoje do cenário do semiárido e a partir dela, dessa tecnologia tão simples, a gente desencadeou tanta coisa, por isso que eu acho que isso é inovador, entendeu (E02_EC2)?

Outra mudança percebida na cultura do ambiente do Semiárido refere-se à valorização da questão da estocagem de água. Os cursos de capacitação para as famílias beneficiadas trouxeram uma grande contribuição para as comunidades nesse sentido, e as famílias passaram a ter maior consciência sobre a questão hídrica, como relata o Entrevistado 03.

É uma mudança física, mas também tem a história da consciência. Então, quando as famílias participam de forma ativa do curso, elas aprendem muita coisa. A gente vê que tem muita mudança também da consciência de cada família. [...] A família tem uma tecnologia que ela, ali, vai armazenar água, a vida dela se torna mais fácil. Tem a mudança de hábito, a família vai passar a economizar mais água. Então, tem vários... se eu for citar, tem ene mudanças na vida das famílias (E03_EC2).

As melhorias nas condições de vida são identificadas em vários aspectos. Um dos primeiros pontos diz respeito à questão da segurança alimentar das famílias por conta da boa qualidade da água consumida e, como consequência direta, uma melhoria das suas condições de saúde. Um exemplo está na redução da taxa da mortalidade infantil, diretamente afetada pela boa qualidade da água estocada, e estimada em 91\%, no período entre 1999 e 2015, considerando-se os índices de mortalidade infantil como resultado das seguintes doenças nas crianças de 0 a 4 anos na Região Nordeste (Ministério da Saúde, 2018): (1) Cólera; (2) Salmonela; (3) Outras infecções intestinais bacterianas; (4) Amebíase; (5) Outras doenças intestinais por protozoários; (6) Diarreia e gastroenterite.

O segundo ponto alude a uma questão de gênero: melhoria da condição de vida das mulheres, historicamente responsáveis pelo abastecimento de água para as atividades domésticas, conforme relato do Entrevistado 04.

Tem um impacto direto na vida das mulheres. Você imaginar, por exemplo, que os cálculos que a gente fez lá em 2000, uma pessoa pra abastecer uma casa, ela gastava em horas 46 dias por ano, em tempo pra abastecer a casa...[...] Num encontro que a gente tava, uma mulher pegou o microfone e disse assim: [“_olhe, eu quero dizer que essa cisterna foi revolucionária na minha vida. Hoje eu tenho $\overline{65}$ anos e eu sou muito grata em ter recebido essa cisterna. Minha vida mudou completamente. Agora, imagine se eu tivesse recebido essa cisterna há 30 anos!’]...e aí pairou...o silêncio (E04_EC2)!

Revista de Gestão Social e Ambiental - RGSA, São Paulo, v. 13, n. 3, p. 44-59, set./dez. 2019. 
No que se refere a Atendimento aos Interesses Coletivos, o P1MC vem reforçar que a água potável é um direito, por se tratar da garantia de um bem indispensável à vida da coletividade. Destaca-se também a questão da consciência agroecológica, bastante discutida nos cursos de capacitação e que consegue promover um novo olhar para as famílias sobre desmatamento de árvores, queimadas, utilização de venenos, que interessam a toda a comunidade. Desta forma, dissemina-se que fazer a gestão da água vai muito além da utilização da água da cisterna, compreende, por exemplo, a preservação da vegetação nativa, que impacta na umidade do ambiente porque mata os micro-organismos do solo, importantes na manutenção da temperatura.

Nesta análise da categoria Valor Social, observou-se que o P1MC promove a obtenção de práticas e respostas que tornam o ambiente mais colaborativo entre os atores sociais, organizacionais e institucionais, proporcionando novas dinâmicas em sociedade para a discussão do problema do abastecimento irregular de água potável no semiárido e propiciando transformação social para a região.

A última categoria da dimensão Resultado, denominada Retornos Sociopolíticos, será inicialmente analisada pelo indicador Empoderamento Social. Este indicador foi observado principalmente nos atores sociais que fazem parte da cadeia relacionada ao P1MC: são empoderados não só os beneficiários da iniciativa, mas também os agricultores, as associações e comissões comunitárias, pelo envolvimento e fortalecimento de suas convicções em torno de melhorar a qualidade de vida da sua comunidade.

Além disso, há um destaque especial para o empoderamento feminino. O relato do Entrevistado 04 ilustra este novo cenário.

\begin{abstract}
Então, mudou muito, mudou bastante. [...] As mulheres hoje estão mais empoderadas a partir das capacitações, a partir do Bolsa Família. Elas estão mais empoderadas, elas participam mais das associações, das reuniões, elas tomam decisão, as mulheres tomam decisões. Então, as famílias estão mais empoderadas dos seus direitos, dessa questão das reformas. Então, quando ela participa da reunião, que é debatido vários temas, elas cada vez mais... elas se empoderam, elas ficam empoderadas dos seus diretos, que a água não é um favor, é um direito (E04_EC2).
\end{abstract}

No que concerne às Respostas Adjacentes, que fazem parte do contexto dos resultados indiretos do $\mathrm{P} 1 \mathrm{MC}$, podem-se destacar alguns temas que remetem a respostas positivas como, por exemplo, a movimentação da economia local, uma vez que a compra do material para a construção das cisternas é toda realizada no comércio local ou em municípios da região, dinamizando também a economia regional. Além disso, com os recursos aplicados nos cursos de treinamento, há a formação de mão-de-obra especializada para a construção das cisternas. É válido salientar que estes pedreiros não só continuam sendo empregados na construção de cisternas, bem como sendo incorporados como profissionais em outros projetos do governo (Campos \& Alves, 2015).

Outro ponto de relevância e convergência entre os entrevistados foi o aumento da frequência escolar em decorrência do P1MC: "O aluno indo mais à escola, você pode imaginar todo um benefício advindo apenas do acesso à água de qualidade (E06_EC2).

A expansão desta iniciativa para territórios internacionais está expressa na transferência desta tecnologia para diferentes países, sendo também uma das respostas adjacentes do programa, recriando a iniciativa de IS ao considerar outros contextos para implementação, como ressalta o Entrevistado 05.

Eu levei o Programa Um Milhão de Cisternas para o Haiti. A Embrapa foi que levou. Inclusive, quando nós fomos convidados, foi junto com uma das organizações filiadas à ASA, né, aqui de Juazeiro da Bahia. E foi um sucesso tremendo isso no Haiti, porque mesmo no terremoto, aquele terremoto que ocorreu, muito grande [em 2010], as cisternas não tiveram nenhum problema, resistiram ao terremoto tranquilamente. (E05_EC2). 
Além disso, a ampliação do P1MC estimulou a criação de dois programas que cumprem a mesma filosofia de estocagem de água: o Programa 1 Terra, 2 Águas, em que são experimentadas várias tecnologias de captação de armazenamento de água para a produção de alimentos para os agricultores locais e o Programa Cisternas nas Escolas, que provê água para as escolas rurais por meio das cisternas.

Ao analisar a categoria Retornos Sociopolíticos, entende-se que tem havido um fortalecimento da coletividade por obtenção das respostas sociais não diretamente relacionadas ao P1MC, o que corrobora também o caráter institucional do programa.

\section{CONSIDERAÇÕES FINAIS}

A análise dos indicadores apontados no modelo de Medeiros (2018) sobre os dados coletados mostrou que o P1MC apresenta-se em fase de mudança sistêmica, que considera que a iniciativa de IS está institucionalizada, indicando que a expansão do programa tem proporcionado uma mudança na forma de pensar da sociedade no tocante ao semiárido brasileiro, por meio de novas práticas sociais incorporadas a esta região.

Os pontos de destaque entre a etapa esperada para o modelo na fase de mudança sistêmica e as análises realizadas neste caso do P1MC envolvem a participação dos atores organizacionais, apresentando-se como protagonistas, desempenhando diversos papéis neste processo, desde o seu surgimento até o estágio de desenvolvimento atual; a capacidade do $\mathrm{P} 1 \mathrm{MC}$ se reinventar, assumindo outros escopos; e o empoderamento da sociedade, possibilitando ações de mudança e transformação social, uma vez que desenvolve novas capacidades técnicas e relacionais nos atores beneficiários envolvidos, reforçando a sua autoestima.

Embora as respostas do P1MC estejam sendo positivas ao longo do tempo para os territórios, considera-se que o percurso das iniciativas de ISS, como apontado no Modelo Teórico da Expansão de Iniciativas de IS (Medeiros, 2018), é sempre não-linear. Desta forma, apesar de o programa estar proporcionando mudança sistêmica para a região semiárida brasileira, não pode ser desconsiderada a hipótese de desinstitucionalização da iniciativa, que pode ser provocada por uma mudança no ambiente externo, devido à ação de grupos que se opõem à estrutura em pauta (Tolbert \& Zucker, 1999), podendo criar uma nova trajetória para a iniciativa de IS. Por outro lado, o programa pode dar origem a novas iniciativas de IS, que se apoiam nesta primeira inovação para potencializar outras.

A análise realizada valida o caráter top-down do $\mathrm{P} 1 \mathrm{MC}$, uma vez que a determinação da gestão das atividades propostas pela política pública vem a partir de diretrizes formalizadas em lei pelo Estado (ator institucional).

Por outro lado, observa-se uma expressiva participação das unidades executoras (atores organizacionais) no que concerne à execução da política pública em nível local e na discussão dos procedimentos operacionais, uma vez que interagem de forma muito próxima aos atores sociais (beneficiários e seus representantes) na execução das atividades. Esses atores organizacionais, em contato direto com os atores sociais das localidades, absorvem novas práticas para melhorias na execução do programa nos territórios (abordagem bottom-up), onde necessitam, muitas vezes, de tratamentos operacionais diferenciados, e concedem este aprendizado aos atores institucionais. Vale ressaltar que muitas vezes os atores institucionais (atores do governo, neste caso) podem desempenhar papéis de atores organizacionais, quando assumem a execução da política pública nas diversas localidades onde o programa tem sido implementado, podendo assumir o comando da gestão da iniciativa nos territórios.

Ao final da análise, como conclusão, corrobora-se o pressuposto inicial de que o Programa 1 Milhão de Cisternas segue um percurso de expansão por meio de uma abordagem de gestão tanto top-down quanto bottom-up, validando ambas as abordagens para esta iniciativa de inovação social, ressaltando o papel exercido pelos atores organizacionais no processo, e, referendando, seu caráter não-linear.

Revista de Gestão Social e Ambiental - RGSA, São Paulo, v. 13, n. 3, p. 44-59, set./dez. 2019. 
Considerando-se o referencial de análise utilizado nesta pesquisa, e como indicação para aprimoramento metodológico, sugere-se que o Modelo Teórico da Expansão de Iniciativas de IS (Medeiros, 2018) seja aplicado em outros casos para que se possa validar de forma mais específica a categoria Mobilização de Atores, que está apresentada de forma bastante genérica e não aponta os diversos papéis que os atores podem assumir durante o percurso de expansão de uma iniciativa de IS.

\section{REFERÊNCIAS}

André, I. \& Abreu A (2006). Dimensões e espaços da inovação social. Finisterra, 41(81), 121-141. Articulação Semiárido Brasileiro (2018). Ações - P1MC. Recuperado em 5 fev. 2018, de www.asabrasil.org.br/acoes/p1mc

Assogba, Y. (2010). Théorie systémique de l'action sociale et innovation sociale. Alliance de recherche université-communauté/innovation sociale et développement des communautés, Université du Québec en Outaouais (UQO), Quebec, Canadá: Recherches, 31.

Bacon, N., Faizullah, N., Mulgan, G. \& Woodcraft, S. (2008). Transformers: how local areas innovate to address changing social needs. London, England: National Endowment for Science, Technology and the Arts.

Bardin, L (2011). Análise de conteúdo. São Paulo, SP: Edições 70.

Borges, M. A. (2017), Dinâmica das parcerias intersetoriais em iniciativas de inovação social, Tese de doutorado, Universidade de Santa Catarina, Florianópolis-SC.

Bureau of European Policy Advisers (2010). Empowering people, driving change: social innovation in the European Union. Luxembourg, Belgiam: European Communities.

Cajaiba-Santana, G. (2014). Social innovation: moving the field forward: a conceptual framework. Technological Forecasting and Social Change, 82, 42 - 51.

Campos, A. \& Alves, A. M.. (2015). Programa Cisternas, uma ferramenta poderosa contra a pobreza. In: Santos, J. M. dos. (Org.) Cadernos de Estudos Desenvolvimento Social em Debate, (23), 118-135, Brasília-DF: Ministério do Desenvolvimento Social e Combate à Fome; Secretaria de Avaliação e Gestão da Informação.

Caulier-Grice, J., Davies, A., Patrick, R. and Norman, W. (2012). Defining social innovation. a deliverable of the project: the theoretical, empirical and policy foundations for building social innovation in Europe (Tepsie). European Commission - 7th Framework Programme. European Commission: DG Research, Brussels.

Choi, N. \& Majumdar, S. (2015). Social innovation: towards a conceptualization. In: Majumdar, S., Guha, S. \& Marakkath, N. (Ed.). Technology and Innovation for Social Change, 734. New Delhi: Springer India.

Cloutier, J. (2003), Qu'est-ce que l'innovation sociale? Centre de Recherche sur lês innovattions sociales, Montreal.

Correia, S. E. N. (2015). O papel do ator organizacional na inovação social. Tese de Doutorado, Universidade Federal de Pernambuco, Recife-PE.

Escola Nacional de Administração Pública (2016). Novo marco legal para a implementação do Programa Cisternas. Recuperado em 9 fev. 2018 de http://repositorio.enap.gov.br/handle/1/2711.

Flick, U. (2009). Introdução à pesquisa qualitativa. Porto Alegre, RS: Artmed.

Gil, A. C. (2010). Como elaborar projetos de pesquisa. (5a ed.) São Paulo-SP: Atlas. 
Have, R. P. V. D. \& Rubalcaba, L. (2016). Social innovation research: an emerging area of innovation studies? Research Policy, 45(9), 1923-1935.

Horst, L. V. M. and Freitas, C. C. G. (2016), "Desenvolvimento sustentável e inovação social: a reciclagem sob a perspectiva da tecnologia social”, Revista Tecnologia e Sociedade, Curitiba, 12(26), 19-41, set-dec.

Howaldt, J., Domanski, D. and Kaletka, C. (2016), "Social innovation: towards a new innovation paradigm”, RAM - Revista Administração Mackenzie (Mackenzie Management Review), 17(6), Special Edition, 20-44.

João, I. S. (2014). Modelo de gestão da inovação social para empresas sociais. (Tese de Doutorado). Faculdade de Economia, Administração e Contabilidade de Ribeirão Preto, Universidade de São Paulo, Ribeirão Preto-SP.

Lévesque, B. (2002). Les entreprises d'économie sociale, plus porteuses d'innovations sociales que les autres? In: Colloque du Cqrs au Congres de L'acfas, 2001, Cahiers du Crises, Montreal, 2(5).

Lopes, D. P. T., Vieira, N., Barbosa, A. C. Q. \& Parente, C. (2015). Inovação gerencial e inovação social: pensando para além da inovação tecnológica. In Anais do Congresso Latino-Americano de Gestão da Tecnologia, 16, Porto Alegre, RS.

Medeiros, C. B. (2018). Expansão de iniciativas de inovação social: uma proposição adaptativa para análise de percursos. Tese de Doutorado, Universidade Federal de Pernambuco, Recife-PE.

Ministério da Saúde (2018). Sistema de informações sobre mortalidade - SIM. Recuperado em 19 fev. 2018, de: www.tabnet.datasus.gov.br

Mulgan, G. (2006). The process of social innovation. Innovations, 1(2), 145-162.

Mulgan, G., Tucker, S., Ali R. \& Sanders, B. (2007). Social Innovation: what it is, why it matters and how it can be accelerated. London: The Basingstoke Press.

Murray, R., Caulier-Grice, J. \& Mulgan, G (2010). The open book of social innovation. London: Nesta/The Young Foundation.

Organização para a Cooperação e Desenvolvimento Econômico (2011). Introduction: transforming innovation to address social challenges. Paris, France: Harayama, Y. \& Nitta, Y..

Rollin, J. \& Vincent, V. (2007). Acteurs et processus d'innovation sociale au Québec. Québec, Canadá: Université du Québec.

Schmitz, B., Krlev, G., Mildenberger, G., Bund, E. \& Hubrich, D. (2013). Paving the way to measurement - a blueprint for social innovation metrics. A short guide to the research for policy makers. A deliverable of the project: "The theoretical, empirical and policy foundations for building social innovation in Europe" (Tepsie), European Commission - 7th Framework

Programme. Brussels, Belgium: European Commission.

Tardif, C. \& Harrisson, D. (2005). Complémentarité, convergence et transversalité: la conceptualisation de l'innovation sociale au Crises. Cahiers du Crises. Québec.

Tolbert, P.S. \& Zucker, L.G. (1999). A institucionalização da teoria institucional, In: Handbook de estudos Organizacionais. Modelos de análises e novas questões em Estudos Organizacionais. (1), 196-218. São Paulo-SP: Atlas.

Tulder, R. V., Seitanidi, M. M., Crane, A. \& Brammer, S. (2016). Enhancing the impact of crosssector partnerships. Journal of Business Ethics, 135(1), 1-17.

Turker, D. \& Vural, C. A. (2017). Embedding social innovation process into the institutional context: voids or supports. Technological Forecasting Social Changes, (119), 98-113 
